\title{
Correspondence
}

\section{Criteria of death}

SIR

The report on the criteria of death by the Danish Council of Ethics (1) is a truly extraordinary document. Its insistence that the criteria be grounded in 'everyday experience' rightly strikes Christopher Pallis (2) as ambiguous dependent as it is upon whose experience (a physician's or a layperson's) is used. But one should not be too quick to dismiss the DCE's conclusion, even if one agrees with Dr Pallis - as I do - that equating death solely with cessation of cardiac functioning would produce absurd results. When we dismiss the DCE, we miss the chance to address not just the concerns of the public - which are manifest in its less than enthusiastic support for organ transplantation - but also the unease of physicians and nurses involved in organ harvesting, who are unsettled by the superficial resemblance of an artificially maintained cadaver to any other critically ill patient on life support (3). As David Lamb notes (4), physicians should avoid telling the media that a 'brain-dead' patient 'died' after the 'life-support machines' were withdrawn; more important, we need to engage in basic education of the public about the reasons that the same underlying phenomenon - death - is measured when all brain (or brainstem) functions have ceased irreversibly as when cardio-respiratory functions have ceased irreversibly $(5,6)$.

Regrettably, however, Doctor Lamb adds confusion on another point in the midst of his otherwise devastating dissection of the DCE position. Doctor Lamb correctly notes that having separate criteria of 'brain-death' for organ donors 'perpetuates an absurd belief in a special kind of death', and that supporters of brain-based definitions disserve their own cause when they attempt to link their definitions with organ transplantation.
But he confuses the determination of death with another issue - when is it appropriate to forego life support? when he adds that 'long before cardiac transplantation...there were profound ethical discussions concerning the value of ventilating to asystole when treatment for patients in irreversible apnoeic coma was obviously hopeless and increasingly gruesome'. 'Coma' is a living state, although the ad hoc Harvard Committee got us all off on the wrong foot in 1968 by using the term 'irreversible coma' in the title of its famous report on the 'definition' of death (7).

The debate about putting 'hopeless' comatose patients through 'gruesome' treatment is important in its own right. If anything, it is a much more controversial issue than that of determining death (at least outside of the DCE's meeting chambers). But it is a separate issue. "When all brain functions have ceased irreversibly' is one answer to the question 'When should mechanical ventilation be stopped?' but not necessarily the only answer. Conversely, 'When a return to consciousness is very unlikely' is one answer to the question 'When is a patient dead?' but not an answer that is by itself sufficient in any country of which I am aware. Instead, 'When a return to consciousness is very unlikely' is the answer that many people give to the question 'When should mechanical ventilation be stopped?' and 'When all brain functions have ceased irreversibly' has generally been accepted as one answer to the question 'When is a person dead?'.

Professor Lamb is correct that the 'case for brain death should stand or fall on its own clinical and theoretical merits'. In an empirical study for the President's Commission, organ donation was not even under consideration for more than 80 per cent of the patients whose deaths were diagnosed based upon neurological (rather than cardio-respiratory) criteria (5). Thus, we would need 'brain-death' criteria to make appropriate determinations of the status of many ventilated patients even were there no organ transplant programmes; likewise, 'profound ethical discussions' will continue about the extent of ventilation and other forms of life-prolonging technology that is appropriate even if treatment is ceased for some such patients on the ground that they have become brain-dead corpses.

\section{References}

(1) Rix B A. Danish ethics counci rejects brain death as the criterio of death. Fournal of medical ethic 1990; 16:5-7.

(2) Pallis C. Return to Elsinore. Fourmal of medical ethics 1990; 16:10-13.

(3) Youngner S J et al. Psychological and ethical implications of organ retrieval. New England journal of medicine 1985; 313:321-324.

(4) Lamb D. Wanting it both ways. Fournal of medical ethics 1990; 16: 8-9.

(5) President's Commission for the Study of Ethical Problems in Medicine and Biomedical and Behavioral Research. Defining death. Washington: Government Printing Office, 1981.

(6) Pallis C. $A B C$ of brainstem death. London: British medical journal 1983.

(7) Ad hoc committee of the Harvard Medical School to examine the definition of brain death. A $\underset{\varnothing}{0}$ definition of irreversible coma. Fournal of the American Medical Association 1968; 205:337-340.

ALEXANDER MORGAN CAPRON The Law Center, University of Southern Califormia, University Park, Los Angeles, 90089-0071, USA 